\title{
Context matters
}

\section{Clementina Acedo}

Published online: 18 December 2010

(C) UNESCO IBE 2010

I am pleased to introduce this ambitious and thought-provoking issue of Prospects, which could well have been called "Context Matters". Its merits extend beyond publishing sound peer-reviewed academic articles to producing well-grounded, scholarly, and reliable work that responds to today's educational questions and policy needs. The articles in this volume aim to fill significant gaps in the educational literature; they range from the first annotated bibliography on psychosocial aspects of education in humanitarian settings to a one-of-akind call to UNESCO to undertake an international project that will gather and analyze existing knowledge about teaching practices and teacher training in developing countries. The contributors to this issue inhabit a vast spectrum of cultures, represent different horizons of thought, and belong to different generations. Despite these differences, the articles presented in this issue have two qualities in common.

First, the articles deal with fundamental issues that are relevant to education today, including academic freedom, policy borrowing, globalization, and humanitarian curricula. Second, despite the diversity of topics tackled in this volume, the main themes of the articles are interwoven. A recurring line of argument throughout this volume is the need to be sensitive to the context, whether in research, policy-making, or pedagogical practice. This idea is thoroughly illustrated, for instance, by McGinn and Shiefelbein' initiative to systematize what we know about effective methods of teaching and teacher training, based on their relevant contents and contexts, and by Crossley's plea to do more to acknowledge the influence and impact of contextual factors in educational research and development cooperation. In addition, all the articles presented in the Open File of this issue stress the importance of carefully adapting imported western models to the national/local context, while also discussing the fine line between imposition and voluntary borrowing of educational models.

The issue opens with two powerful Viewpoints, authored by leading scholars in comparative education: Michael Crossley, and Noel McGinn and Ernesto Schiefelbein.

Michael Crossley reframes the questions and fundamental beliefs that have preoccupied him throughout his work and life, including the strong conviction that contextual factors

C. Acedo $(\triangle)$

UNESCO IBE, P.O. BOX 199, 1211 Geneva 20, Switzerland

e-mail: c.acedo@ibe.unesco.org 
are crucial in educational research and international development cooperation. He questions fashionable concepts such as "best practice", as a search for one best model in education, which can be uncritically transferred and sometimes imposed elsewhere, without taking into account the actual context of the new settings. He considers the situation of small states: they have limited access to international research and development funds, are not involved in the shaping of international agendas, and often find that their own development priorities are overlooked. Crossley calls for efforts to strengthen local involvement in policy-oriented research, for strategies that are well adapted to local realities, for the involvement of local staff in the policy-making process, and for careful incountry analysis of the relevance of international research and policy advice. Without these, any internationally-driven education initiatives and reforms are bound to fail; far too many already have.

Noel McGinn and Ernesto Schiefelbein further highlight the comparative importance of pedagogical practices in various contexts. They start by defining teacher effectiveness and quality of teaching, and point out that these concepts have alternative meanings. Their discussion includes a concrete proposal to find and share research and experience-based information about factors that influence the quality of teaching in developing countries. They suggest that teams could compile locally-developed knowledge about three topics: What teaching practices are most effective in classrooms? How do the teachers who use those practices learn them? How and what should teacher training institutions teach teachers so that they will use effective practices? They believe that UNESCO could lead this worldwide effort, which aims to build a knowledge base for each of these three topic questions. The authors invite colleagues in, and with experience in, developing countries, to share their knowledge of teaching practices.

Next, through a case study of the Comparative Education Review, Tom G. Griffiths and Lisa Knezevic explore how Immanuel Wallerstein's world-systems analysis has been used and interpreted in the field, and argue for a more vigorous engagement with its application to comparative theorizing and research. This, the authors maintain, would provide a better understanding of the nature and global spread of mass educational systems and reforms, while also offering a useful "framework for our times, by responding directly to questions of inequality, justice, and democracy at a world-system level, and the actual and potential role of education in advancing such ideas". The ideas expressed in this article are naturally in sync with the Viewpoints of Crossley, and McGinn and Schiefelbein, as they draw attention to a necessary balance between core and diversified content and to alternative "configurations of knowledge", to which they respond at both the national and worldsystem levels.

Using David Johnson's five metaphors to describe the historical and political forces that shape educational policy trajectories (the politics of telling, rebelling, compelling, selling, and gelling), Charlene Tan analyses the case of Singapore and Cambodia in an "era of globalization". Singapore is characterized, in the author's view, by the "politics of selling": the country has more control over its policy environments and is able to strategically "buy" selected educational policies, which are likely to promote its national economic growth and global competitiveness. The "politics of compelling" constitute an appropriate framework for Cambodia, a heavily indebted, poorer country, which has to negotiate its relationships with the international donor community. Although these two countries are at different stages, they face similar challenges, related to shifting from a traditional teachercentred and textbook-based approach to a more student-centred and ICT-based approachchanges accomplished through the process of adopting unreservedly imported policies. Tan argues in favour of the "politics of gelling" for both Cambodia and Singapore; through this 
strategy these countries could combine foreign and indigenous sources of knowledge involving different interest groups and thus take the lead in educational reforms.

A similar predicament is present in Ali Ibrahim's article about the ways in which foreign transfer has influenced Egyptian education. The author follows its complicated trajectory, from voluntary imitation (during the reign of Muhammad Ali) to imposed reforms (under British occupation) and to the current ambiguity of education transfer, which is "neither a simple dynamic of local actors making unfettered choices in a free market of ideas nor a simple process of international actors imposing ideas on unwilling local actors". In the absence of a common, coherent education philosophy, international organizations and various interest groups (including neoliberals, conservative Islamists, and socialists) compete to fill the vacuum and to bring their own agenda to the education policy. Ibrahim concludes that the current system of Egyptian education is the result of inappropriately adapted foreign transfers coupled with domestic interest in spreading education with little attention to its quality. In this complex context, initiatives such as decentralization and community participation, or the use of active-learning methods and the integration of technology into teaching and learning, have largely failed. Thus, the author describes a paradoxical situation, in which the Egyptian government and international organizations continue to support the rhetoric of reform, despite the fact that efforts at reform are not visible and often not even feasible.

Michael H. Romanowski and Ramzi Nasser examine the concept of "academic freedom", as understood by faculty at a major university in a Gulf Cooperation Council (GCC) country. Their article adds naturally to the literature on policy borrowing vs. local context: indeed, academic freedom cannot be separated from the political, cultural, and political milieu of Arab society and the Arab world. The growth and reform of higher education, the authors show, challenges the delicate balance between academic freedom and Arab cultural values. Their findings indicate that faculty members have complex and often contradictory understandings of academic freedom and related responsibilities and often engage in selfcensorship.

The section Trends/Cases features two articles, which have the ambitious goal of being the first comprehensive literature reviews on their topics in a specific context.

Amita Chudgar and Najeeb Shafiq review research on the relationship between family and community, on one hand, and educational outcomes, on the other hand, in South Asia. They analyze the variables of family socioeconomic status, parental education, family structure, and religion and caste. At the community level, they examine the limited research on the relationships between economic, cultural, and social characteristics and children's educational outcomes. Their literature review presents several consistent findings about the influence of family and community characteristics on educational outcomes. To offer two examples, higher levels of parental education, higher family income, and higher rates of return to education are associated with better educational outcomes, and the availability and quality of schools in a community is critical in determining educational outcomes. It also identifies several areas where further research is needed. These include quantitative research in Afghanistan, Bhutan, Burma, and the Maldives; studies on how the behaviour of educated parents differs from that of less educated parents; more studies on urban communities; and the influence of community-level variables such as access to credit, and the traditions of hypergamy, dowry, and patrilocal exogamy.

Gonzalo Retamal and Maria Low examine the links between psychosocial aspects of education and the curriculum in humanitarian settings. Their annotated bibliography, the first of its kind in the field, is an attempt to identify and strengthen a constructive dialogue between educators and psychologists working in the humanitarian field and to highlight 
important South-South contributions. The bibliography draws effectively on the vast range of recent scholarship in psychology and education, which is discussed in the substantial and useful notes accompanying each entry. The review highlights the healing value of humanitarian curricula, as its authors argue for the need to incorporate evaluation instruments into the psychosocial domain of school curricula in complex humanitarian emergencies.

The issue concludes with an evocative profile of Julio Larrea, the prominent Ecuadorian scholar whose work is pivotal to the understanding of education development in Latin America. Even today, at institutions such as the Central University of Venezuela, students are often reminded about the "Three Ls": Larroyo, Luzuriaga and Larrea, scholars who contributed enormously to the growth and advancement of teacher education in Latin America. Larrea also remains in the public consciousness as the editor of Nueva Era, a journal influenced by the New School movement, which promoted active learning and, under Larrea's editorship, became a well-respected international publication. The author this Profile, Elba Martinez de Larrea, shows a tremendous aptness of evocative language, which brings to life a detailed reconstruction of his life and work, characterized by intellectual lucidity, profound knowledge, and sheer passion.

Acknowledgments My special thanks to Simona Popa for her significant contribution to the writing of this editorial. 